\title{
Acquisition of running in the straight alley following experience with response-independent food
}

\author{
RICHARD S. CALEF, RONALD A. METZ, TAMARA L. ATKINSON, \\ RUTH C. PELLERZI, and KATHRYN S. TAYLOR \\ West Virginia Wesleyan College, Buckhannon, West Virginia \\ and \\ E. SCOTT GELLER \\ Virginia Polytechnic Institute and State University, Blacksburg, Virginia
}

\begin{abstract}
During Phase 1, rats received contingent reinforcement (food), noncontingent reward, or no treatment in an operant chamber. The results, which did not support a "learned-helplessness" interpretation, showed response-independent food to facilitate rather than inhibit the acquisition of a running response in the straight alley during Phase 2.
\end{abstract}

Dogs or rats exposed to inescapable (uncontrollable) shock have performed worse with later escape learning than subjects receiving an equivalent amount of prior escapable shock or no shock. This phenomenon has been called "learned helplessness" (e.g., Maier, Albin, \& Testa, 1973; Overmier \& Seligman, 1967; Seligman \& Beagley, 1975). Recently, learned helplessness was applied to an appetitive situation in which deficits in instrumental responding for food were also observed in rats that had been given prior exposure to noncontingent food (Oakes, Rosenblum, \& Fox, 1982; Seligman, 1975; Wheatley, Welker, \& Miles, 1977).

It was expected that noncontingent reinforcement would produce results similar to those produced by inescapable shock, since, according to Maier and Seligman (1976), "learned helplessness" results from subjects' interpreting that reinforcement is uncontrollable or response independent. In other words, Maier and Seligman seemed to suggest that animals receiving responseindependent consequences learned the concept of uncontrollability of the events that followed behavior and that this perception of uncontrollability caused the learning deficits. Thus, that noncontingent positive reinforcement also produced deficits in learning was no surprise, since the concept of uncontrollability of the event that follows responding should also be learned in the appetitive "helplessness" paradigm.

The purpose of the present study was to provide further evidence that learned helplessness in the appetitive situation is a reliable phenomenon. Most appetitive helplessness studies have searched for deficits in the

The author's mailing address is: Department of Psychology, West Virginia Wesleyan College, Buckhannon, West Virginia 26201 . acquisition of a barpressing response following noncontingent rewards. The present investigation attempted to study the effects of response-independent food on the acquisition of a running response in the straight alley. The learned-helplessness hypothesis predicts that rats presented with noncontingent food should acquire the running response at a slower rate than would rats treated with contingent food or no food (cf. Maier, Seligman, \& Solomon, 1969).

\section{METHOD}

\section{Subjects}

The subjects were 24 experimentally naive male albino rats of the Sprague-Dawley strain; they were approximately 90 days old at the beginning of the experiment. The animals were acquired from Flow Laboratories, Dublin, Virginia, where they had been bred and reared. They were maintained on ad-lib water and were run during the light phase of the 12-h-dark/12-h-light housing schedule.

\section{Apparatus}

A straight-alley food runway and three operant chambers were used in this experiment. The alley was composed of a $33.02-\mathrm{cm}$ gray startbox, a $66.04-\mathrm{cm}$ gray runway section, and a $33.48-\mathrm{cm}$ gray goalbox. The inner width and height of each section of the runway were 12.5 and $16.5 \mathrm{~cm}$, respectively. The walls and floor of the runway were constructed of plywood. Photocell and clock circuitry provided an independent measure of traversal time over the last $30.5-\mathrm{cm}(1-\mathrm{ft})$ segment of the run section. The apparatus contained a gray retrace door, separating the goal from the alley section, and an opaque Plexiglas ceiling.

The three operant chambers used were $19.6 \mathrm{~cm}$ wide, $18 \mathrm{~cm}$ high, and $29 \mathrm{~cm}$ long. The sides of the chambers and the ceiling were constructed of clear Plexiglas. Centered on the right-hand panel was a lever $(5 \mathrm{~cm})$ that was $5.5 \mathrm{~cm}$ above the floor. To the right of the lever was a square goal cup that extended to the outside of the chamber so that the experimenter manually could place pellets in it. The goal cup was approximately $5 \mathrm{~cm}$ above the floor. 


\section{Procedure}

Fourteen days prior to the 1st day of training (Day 15), all rats were placed on a 23-h food-deprivation schedule, which was maintained throughout the study. On Days 7-14, the rats were taken from their individual home cages and handled for about 2 min each. On Days 13 and 14, the rats were taken to the experimental laboratory, where they were allowed to explore the start and run sections of the apparatus while the clocks, photocells, and door were operated. On those days, approximately $1 \mathrm{~g}$ of 45 -mg Noyes pellets, identical to the subsequent reinforcement pellets, was incorporated into the rats' daily food ration. The rats then were assigned randomly to one of three groups (8 rats/group).

During Phase 1, a yoked-control design was employed $(.5 \mathrm{~h} /$ day for 3 days), such that Group C (contingent or controllable condition) was shaped to barpress (the response lever was baited with a single pellet for 10 trials) for one pellet per response in an operant chamber, whereas Group NC (noncontingent or noncontrollable condition) received noncontingent reward in another operant chamber at the same time that Group $C$ earned its food. In other words, the amount of food was yoked. When a subject from Group C barpressed, both that subject and its "partner" from Group NC received a pellet in the goal cup. Group NT (no treatment) received no food but occupied an operant chamber (which also contained a lever and a goal cup similar to those in the other chambers) during the same time of day $(.5 \mathrm{~h} / \mathrm{day}$ for 3 days) when Groups C and NC were treated. Group NT did receive the same number of pellets that Groups $C$ and NC consumed during the training session, but they (Group NT) received the pellets in their home cages during their ad-lib (1-h) feeding time immediately following the session.

During Phase 2, all animals were given 48 trials (4 trials/ day) of continuous reinforcement (CRF) training (four pellets) in the straight runway. Trials were administered to four squads of six rats, two per group. The running order of subjects within a squad was randomized from day to day. The intertrial interval was approximately $8 \mathrm{~min}$, since a subject did not receive its second daily trial until all subjects in a squad had completed their first trial. The running trials during Phase 2 were initiated by the rat's being placed in the startbox. After a 3-sec orientation period, the startbox door was opened and the rat was allowed to traverse the runway. Following the rat's entry into the goalbox, the retrace door was dropped. Following consumption of the pellets, the rat was removed from the apparatus to a nearby wire-mesh cage to await the next trial.

\section{RESULTS}

\section{Phase 1: Operant Training}

All the subjects in Group $\mathrm{C}$ learned to barpress. On Days 1, 2, and 3, Group $\mathrm{C}$ barpressed at an average rate of 6,7 , and 8 presses/min, respectively.

\section{Phase 2: Runway Training}

Run times were converted to reciprocals to yield run speeds. Figure 1 illustrates group mean speeds as a function of four-trial blocks. As can be seen in Figure 1, Group NC ran considerably faster than did Groups C and NT during early acquisition (Blocks 4-6). All three groups of rats were running at approximately the same speed during the last four blocks of Phase 2.

A 3 (groups) $\times 4$ (stages) factorial analysis was performed on the data from Blocks 1-12. Stage 1 included the data from Blocks 1-3, Stage 2, the data from Blocks 4-6, Stage 3, the data from Blocks 7-9, and Stage 4, the data from Blocks 10-12. The analysis

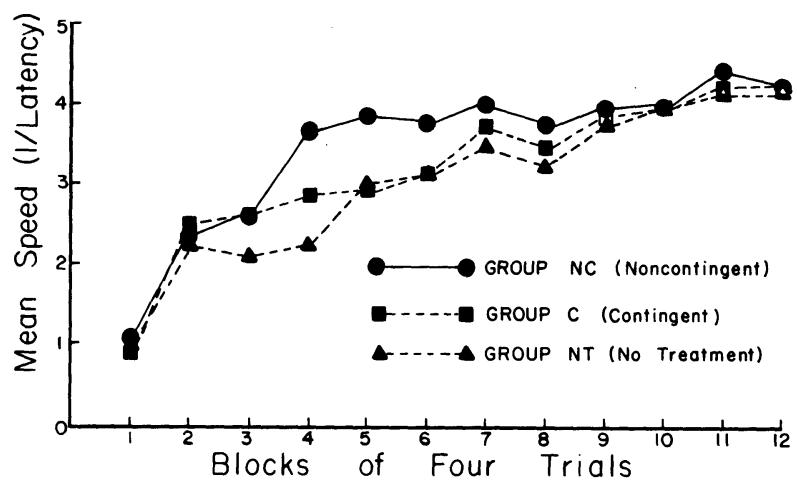

Figure 1. Group mean alley speeds during acquisition as a function of blocks of four trials for rats receiving noncontingent reward (Group NC), contingent reinforcement (Group $\mathrm{C}$ ), and no treatment (Group NT) in an operant chamber.

yielded a significant effect of groups $[F(2,21)=3.49$, $\mathrm{p}<.05]$, a significant effect of blocks $[\mathrm{F}(3,63)=3.17$, $\mathrm{p}<.05]$, and a significant groups $\mathrm{x}$ blocks interaction $[F(6,63)=4.01, p<.01]$. Tukey (a) paired comparisons between group mean running speeds showed that Group NC ran significantly faster than did Groups C and NT at Stage 2 (Blocks 4-6) $(\mathrm{p}<.05)$, but that none of the groups exhibited significantly different speeds at Stages 1, 3, and $4(\mathrm{p}>.10)$.

\section{DISCUSSION}

The findings did not support the hypothesis that noncontrollability would produce slower runway acquisition than would controllability or no treatment. In other words, Group NC, which received response-independent food in the operant chamber, should have learned that their behavior had no control over the consequences or that it was ineffective in producing consistent reward. This learning, in turn, should have produced deficits in acquiring the running response. Instead, the findings showed noncontrollability to produce faster running acquisition than did controllability or no treatment. These findings are particularly nonsupportive of a learned-helplessness interpretation of the effect of receiving response-independent food, since Maier and Seligman (1976) suggested that learning uncontrollability should produce a generalized reduction in motivation. If the rats in Group NC were learning the concept of uncontrollability, why did they initiate a running response sooner than the subjects that may have learned controllability or no concept of control?

The present results imply that the appetitive learned-helplessness model cannot be extended to predict performance in the straight alley and that the findings by Calef, Murray, Modlin, Meekins, and Geller (1981) should not be attributed to a learned-helplessness phenomenon. In that study, subsequent to receiving $C R F$ training in a straight runway, rats were given contingent, noncontingent, or no reinforcement in the operant chamber. The results showed the noncontingent group to be the most resistant to extinction in the runway. Calef et al. interpreted the results in terms of learned helplessness by contending that the response-independent subjects may have been showing a deficit in learning not to respond during extinction.

Both the results of the present study and those of Calef et al. (1981) can be interpreted according to Amsel's (1958) conditioned-frustration theory. Group NC may have learned to antici- 
pate food in the goal cup of the operant chamber. If an approach response in the operant chamber was followed by no food, frustration may have occurred and become conditioned to the chamber cues. Conditioned frustration (rf-sf) elicited by the chamber cues may occasionally have been followed by reward in the goal cup. Hence, Group NC may have learned to approach in the presence of frustration-eliciting stimuli. According to Amsel's (1972) general persistence theory, learning to approach in the presence of frustration-eliciting stimuli. According to Amsel's (1972) persistence theory, learning to approach in the presence of aversive stimuli (rf-sf) should cause subjects the acquisition of a new response or rf-sf during extinction. Hence, rats receiving response-independent food should have acquired the running response faster in the present study than did the control rats because of the generalization of learning to persist in the presence of a disruptive stimulus, and should have shown more resistance to extinction in the Calef et al. study.

It should be noted that the present results support the finding from the aversive-helplessness literature that receiving response-independent reinforcement facilitates learning in the runway. Chen and Amsel (1977) found faster speeds in the runway for rats receiving inescapable shock than for rats receiving no shock. They actually interpreted the results as supporting Amsel's (1972) persistence theory.

Although the present data do not support the results shown by most of the appetitive learned-helplessness studies (e.g., Oakes et al., 1982; Wheatley et al., 1977), it is noteworthy that Beatty and Maki (1979) also showed that noncontingent reinforcement facilitated the acquisition of a new response. It is quite interesting that Beatty and Maki obtained the facilitatory effect of receiving response-independent food on the acquisition of leverpressing, a response that previously has been shown in the literature to be acquired slower by noncontingently reinforced subjects. The contrary findings in the appetitive learnedhelplessness area may be attributed to training procedures that may have been more conducive to the learning of persistence rather than of learned helplessness. It remains for further research to determine what procedures can better differentiate the training of persistence and learned helplessness in the area of appetitive helplessness.

\section{REFERENCES}

AMseL, A. (1958). The role of frustrative nonreward in noncontinuous reward situations. Psychological Bulletin, 55, 102-119.
Amsel, A. (1972). Behavioral habituation, counterconditioning, and a general theory of persistence. In A. H. Black \& W. F. Prokasy (Ed.), Classical conditioning II: Current research and theory. New York: Appleton-Century-Crofts.

Beatty, W. W., \& MaKı, W. S. (1979). Acquisition of instrumental responding following noncontingent reinforcement: Failure to observe "learned laziness" in rats. Bulletin of the Psychonomic Society, 13, 268-271.

Calef, R. S., Murray, D. W., Modlin, P. D., Meekins, B. W., \& Gellen, E. S. (1981). The effects of controllability on extinction. Bulletin of the Psychonomic Society, 17, 241-243.

Chen, J. S., \& Amsel, A. (1977). Prolonged, unsignaled, inescapable shocks increase persistence in subsequent appetitive instrumental learning. Animal Learning \& Behavior, 5, 377-385.

Maier, S. F., Albin, R. W., \& Testa, T. J. (1973). Failure to learn to escape in rats previously exposed to inescapable shock depends on the nature of the escape response. Journal of Comparative and Physiological Psychology, 85, 581-592.

Maier, S. F., \& Seligman, M. E. P. (1976). Learned helplessness: Theory and evidence. Journal of Experimental Psychology: General, 105, 3-46.

Maier, S. F., Seligman, M. E. P., \& Solomon, R. L. (1969). Pavlovian fear conditioning and learned helplessness. In B. A. Campbell \& R. M. Church (Eds.), Punishment and aversive behavior. New York: Appleton-Century-Crofts.

Onkes, W. F., Rosenblum, J. L., \& Fox, P. E. (1982). “Manna from heaven." The effect of noncontingent appetitive reinforcers on learning in rats. Bulletin of the Psychonomic Society, 19, 123-126.

Overmier, J. B., \& Seligman, M. E. P. (1967). Effects of inescapable shock upon subsequent escape and avoidance learning. Journal of Comparative and Physiological Psychology, 63, 23-33.

Seligman, M. E. P. (1975). Helplessness. San Francisco: Freeman. Seligman, M. E. P., \& Beagley, G. (1975). Learned helplessness in the rat. Journal of Comparative and Physiological Psychology, 88, 534-542.

Wheatley, K. L., Welker, R. L., \& Miles, R. C. (1977). Acquisition of barpressing in rats following experience with response-independent food. Animal Learning \& Behavior, 5, 236-242.

(Manuscript received for publication October 19, 1983.) 